\title{
Electron Probe Microanalysis of $U$ and U-alloys... How Hard Can It Be?
}

\author{
Mike Matthews ${ }^{1,2^{*}}$, Stuart Kearns ${ }^{2}$ and Ben Buse ${ }^{2}$ \\ 1. AWE, Aldermaston, Reading, UK. \\ 2. University of Bristol, School of Earth Sciences, Wills Memorial Building, Clifton, UK. \\ * Corresponding author: matthm@hotmail.com
}

Electron probe microanalysis of pure metals and simple alloys should be relatively trivial. However, Uranium metal and its alloys pose some additional problems compared to many other materials. For example, its high atomic number $(Z=92)$ means that it produces a large number of characteristic $x$-ray lines, ranging in energy from $<1 \mathrm{KeV}$ to $>100 \mathrm{KeV}$. Whilst the large number of lines potentially gives a large choice for analysis the K-lines are inaccessible to conventional EPMA and the L-lines can only be efficiently excited at relatively high accelerating voltages $(>25 \mathrm{kV})$. The necessary correction factors for the more accessible M-lines are poorly constrained, in particular for pairings with low element numbers such as $\mathrm{O}$ and $\mathrm{C}$.

The choice of reference material for $U$ is also not trivial. The very high affinity of $U$ metal for $O$ can form a $10-20 \mathrm{~nm}$ thick oxide layer within minutes of polishing, making the metal unsuitable for calibration. $\mathrm{U}$ has a wide range of possible oxidation states, from $\mathrm{UO}$ to $\mathrm{U}_{3} \mathrm{O}_{8}$. Where stoichiometric $\mathrm{UO}_{2}$ can be found it is frequently in the form of sintered powder. Even high pressure sintered $\mathrm{UO}_{2}$ powders retain a significant level of micro-porosity, making it less than ideal for calibration. Synthetically grown $\mathrm{UO}_{2}$, if it can be found, is far superior but still produces consistently high analysis totals for U-metal (Figure 1). Measurement of and correction for the ubiquitous oxide layer on the U metal surface can recover closer to $100 \%$ totals at $15 \mathrm{kV}$ and above. At voltages below this, though, the oxide corrected analyses rapidly deviate from $100 \%$ and produce even poorer analysis totals than without correction for the oxide layer below $10 \mathrm{kV}$.

The Pouchou and Pichoir[1] EPMA method for the determination of mass attenuation coefficients (MACs) was used to measure the compound MACs for both $\mathrm{U}$ and $\mathrm{O}$ in $\mathrm{UO}_{2}$. The resulting values show good agreement with the FFAST[2] and MAC30[3] database values, as shown in tables 1 and 2. Assuming the FFAST database values for $\mathrm{O} \mathrm{K} \alpha$ and $\mathrm{U} \mathrm{M} \alpha$ by $\mathrm{O}$ values for $\mathrm{U} \mathrm{M} \alpha$ and $\mathrm{O} \mathrm{K} \alpha$ by $\mathrm{U}$ were calculated and again showed good agreement with the existing database values (tables 1 and 2). Using the calculated MAC values failed to correct the very poor low voltage analyses. Comparison of EPMA measured U M $\alpha$ k-ratios on U metal against GMRFilm[4], DTSA-II[5] and PENEPMA[6] calculated kratios for both metallic $\mathrm{U}$ and $\mathrm{UO}_{2}$ on $\mathrm{U}$ indicate that the measured samples behave more like metallic $\mathrm{U}$ than oxidised $U$ at low accelerating voltages. Possible explanations are that $i)$ the models for all three programs produce similar erroneous results at low accelerating voltages, or ii) $U$ appears to be less oxidised towards the surface.

The large number of possible U x-ray lines also produces a high probability of interferences: Analysis of $\mathrm{C}$ in $\mathrm{U}$ is complicated by the presence of an obscure $\mathrm{U}$ N6-O4[7] line which is not reported in many software peak overlap tools. This, in combination with its proximity to the $\mathrm{C}$ Ka peak position, means that this overlap can easily be mistaken for a $\sim 3.5 \mathrm{eV}$ shift in the $\mathrm{C} \mathrm{K} \alpha$ peak position. At the vitreous $\mathrm{C}$ peak position the $\mathrm{U}$ line can account for $\sim 40 \%$ of the measured $\mathrm{C} \mathrm{K} \alpha$ signal (Figure 2). If the 'shifted' peak position is used this increases to $\sim 60 \%$ and is therefore the source of a very large potential error in $\mathrm{C}$ analysis. A U N6-O5 line, indicated to be 100x more intense than the N6-O4 line, is not seen in 
measured spectra. However, the electron shell and orbital populations indicate that the O5 orbital should not be occupied if the $U$ atom is not in an excited state, precluding the fluorescence of this line [8].

References:

[1] J-L Pouchou and FMA Pichoir in "Microbeam Analysis 1988", ed. D.E. Newbury, (San Francisco Press, San Francisco) p. 319.

[2] CT Chantler et al., X-Ray Form Factor, Attenuation and Scattering Tables (version 2.1). 2005.

[3] KFJ Heinrich, 11th International Congress on X-ray Optics and Microanalysis (1986), p. 67.

[4] RA Waldo, in "Microbeam Analysis 1988", ed. D.E. Newbury, (San Francisco Press, San

Francisco) p. 310.

[5] NWM Ritchie, J Davis and DE Newbury, Microscopy and Microanalysis. 14 (2008), p. 1176.

[6] X Llovet and F Salvat, IOP Conf. Ser. Mater. Sci. Eng. 109 (2016), p. 012009.

[7] JA Bearden, Rev. Mod. Phys. 39 (1967), p. 78.

[8] The authors gratefully acknowledge funding from AWE, UK.

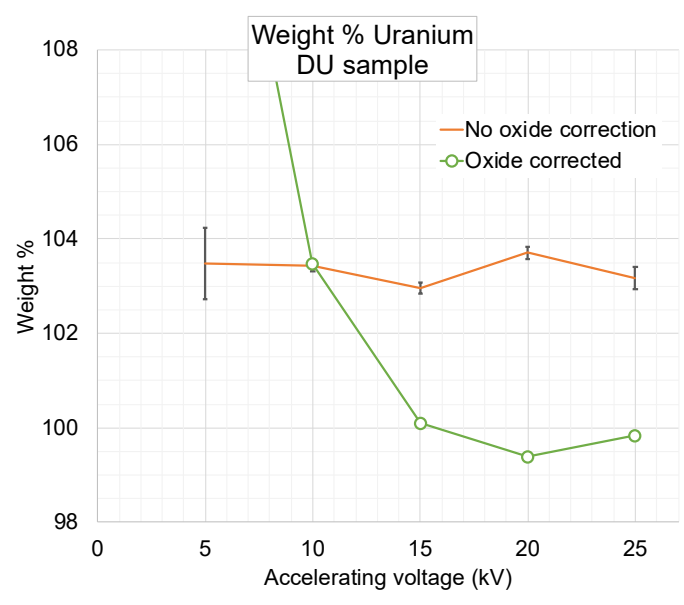

Figure 1. Comparison of analysis totals on a pure U-metal sample, both with and without correction for the surface oxide on the sample.

\begin{tabular}{|c|c|c|c|}
\hline O Ka by & FFAST & MAC30 & P\&P \\
\hline $\mathrm{U}$ & 7498.270 & 11399.210 & 9168.164 \\
\hline $\mathbf{0}$ & 1120.430 & 1180.630 & 1120.430 \\
\hline $\mathrm{UO}_{2}$ & $\mathbf{6 7 4 2 . 4 2 3}$ & $\mathbf{1 0 1 8 8 . 2 0 6}$ & $\mathbf{8 2 1 4 . 4 2 7}$ \\
\hline
\end{tabular}

Table 1. Database and calculated MAC values for $\mathrm{O} \mathrm{Ka}$ absorbed by $\mathrm{U}, \mathrm{O}$ and $\mathrm{UO}_{2}$.

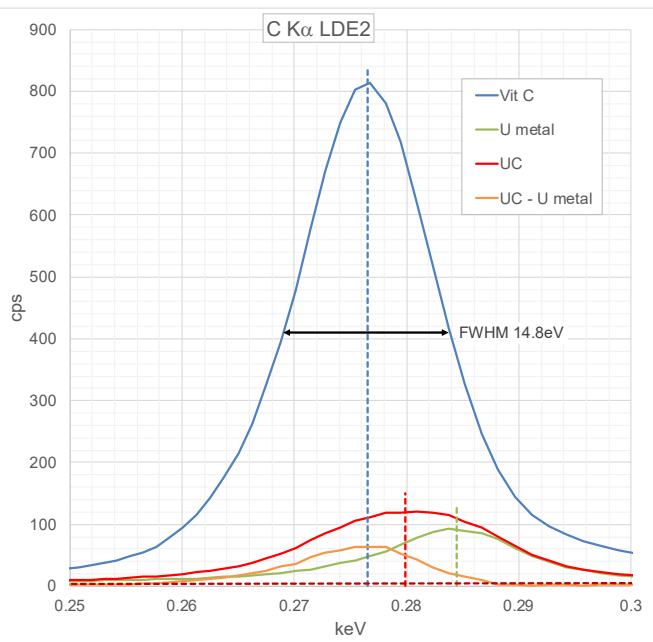

Figure 2. Comparison of x-ray spectra in the region of the $\mathrm{C}$ Ka peak from vitreous $\mathrm{C}$, $\mathrm{U}$ metal, and UC samples, and a calculated residual $\mathrm{C} \mathrm{K \alpha}$ peak after subtraction of the $U$ metal peak from the UC spectrum.

\begin{tabular}{|c|c|c|c|}
\hline U Ma by & FFAST & MAC30 & P\&P \\
\hline $\mathrm{U}$ & 638.870 & 720.830 & 996.839 \\
\hline $\mathbf{O}$ & 174.870 & 183.070 & 174.870 \\
\hline $\mathrm{UO}_{2}$ & $\mathbf{5 8 3 . 8 8 1}$ & $\mathbf{6 5 7 . 1 0 0}$ & $\mathbf{8 9 9 . 4 2 8}$ \\
\hline
\end{tabular}

Table 2. Database and calculated MAC values for $\mathrm{U}$ Ma absorbed by $\mathrm{U}, \mathrm{O}$ and $\mathrm{UO}_{2}$. 